\title{
The mid - term effect of kinesio taping on peak power of quadriceps and hamstring muscles after anterior cruciate ligament reconstruction
}

\author{
Mahdi Amel Khabazan, Hossein Soltani \\ Department of Physical Education and Sport Sciences, Torbat - e Heydarieh Branch, Islamic Azad University, Torbat \\ -e Heidariyeh, Iran.
}

\begin{abstract}
Purpose:

The aim of this study was to assess mid- term effect of Kinesio tape on peak power of quadriceps and hamstrings muscles after $A C L$ reconstruction 24 hours after taping.

Material: $\quad$ Thirty six men who had undergone ACL reconstruction and completed physiotherapy periods (6 months) were assigned to no taping, placebo and taping groups. Peak power was tested before and 24 hours after taping by Isokinetic dynamometry. Data was analyzed by SPSS software 19. ANOVA and post hoc test (LSD) were used for interpretive analysis.

Results: $\quad$ The results showed that the effect of Kinesio tape on peak power of quadriceps muscles at velocities of $180 \% \mathrm{~s}$ and $300 \%$ s was significant. In the hamstring muscles, significant effects were obtained at velocities of $60 \%$, $180 \%$ s \& $300 \%$ s.

Conclusions: Positive impacts of Kinesio tape on muscular peak power among athletes who had ACL reconstruction were observed. Regardless of psychological effect and reducing re - injury fear, Kinesio - tape causes to stabilize and increase effective range of motion of the knee, so it is recommended that in the explosive training, athletes who have ACL reconstruction should use tape to reduce the probability of re-injury and increase muscle power.

Keywords: $\quad$ sport biomechanics, knee ligaments, physical treatments', athletes.
\end{abstract}

\section{Introduction}

Rupture in ACL is very prevalent and its treatment is too costly and time- consuming [1]. Previous studies show that 80 to 250 thousand of ACL injuries occur yearly between ages 15 to 25 years [2]. Reconstruction of this ligament is the most common method of treatment for those who encounter with ACL tear. Special care and physiotherapy after surgical operation, together with the special exercise may help the athlete to return to competitions after some months [1]. The increased rate of ACL tears in youth athletes have been attributed to multiple factors including an increase in early sports specialization and competition, lack of free play and increased awareness of ACL injuries in children [3]. On the other hand, Quadriceps weakness persists after ACL reconstruction. Muscle atrophy and activation failure may contribute [4]. It has been mentioned that ACL reconstruction and injured limb decreased from 5\% to $40 \%$ in strength of the quadriceps muscle $[5,6,7]$. It can be concluded that other factors (physical fitness) such as maximal power is affected by ACL reconstruction. So, Physiotherapist and sport therapists must plan and treat athletes to achieve all these factors in the shortest possible time and reach them to the peak level of their activity. Achieving to muscle maximal power factor is extremely important because it is infrastructure and basic foundation of athletes' skills training. Maximal power factor is considered in rehabilitation programs from $6^{\text {th }}$ month after reconstruction. Plyometric training is a specialized, high-intensity training method which aims to increase sport-specific explosive peak power and

(c) Mahdi Amel Khabazan, Hossein Soltani, 2017

doi:10.15561/20755279.2017.0105 the rate of force development [8]. Plyometric training is applied as muscle peak power in rehabilitation protocols after the sixth month, because it's not only increasing muscle peak power but also neuromuscular coordination. For prevention, rehabilitation and modulating some physiological processes of ACL injury, different methods and tools such as "Kinesio- Tape" were used [9, 10, 1, 11]. Taping is usually used to help recover from overuse and other injuries. Taping can support injuries at the muscletendon units by compressing and limiting movement and secure protective pads, dressings and splints [12]. KT gives support and stability to the joints and muscles without affecting circulation, range of motion and allows for the athletes to exercise with greater intensity [1]. Application of the tape allows the body to move normally, and reacts to the fascia via biomechanical or proprioceptive mechanisms [13]. Some of the researchers assumed that KT can facilitate and stimulate muscle function if its application starts at the origin of the muscle and ends at its insertion [12, 13, 14]. KT could stimulate the fascia and provide higher tension for facilitating the muscle contraction [12, 14]. Before starting explosive exercise such as plyometric exercise, evaluation of the femur's muscles peak power can help to rehabilitator. Peak power of hamstring and quadriceps muscles can be considered as fair criteria and useful signal in the prevention of re-injury and promote a return to sport for injured athletes. Applying KT can help joint stability and increase the muscular power among athletes who underwent ACL reconstruction. Some studies have noted a positive effect of taping on explosive exercise and others have considered it ineffective $[13,15,16]$. Some 
of the studies have researched the effect models of taping in different area of the body. The most recent systematic reviews have concluded that there is little quality evidence to recommend the usage of $\mathrm{KT}$ to prevent or treat musculoskeletal injuries $[17,18]$ and regarding efficacy of KT applications to promote strength gains has recently been reviewed (19). Since previous studies have been conducted on healthy people and athletes and on the other hand, few studies about applying mid -term KT on peak power of the femur's muscles have been done. So the aim of this study was studying mid - term effect (24 hours) of KT on peak power quadriceps and hamstring muscles among athletes who underwent ACL reconstruction.

\section{Material and Methods}

The method of this research was quasi experimental. Statistical population of present research included all of the athletes that had ACL reconstruction. The ACL surgery was performed by an orthopedic surgeon using a doublebundle method (allograft) followed by an effectively ACL reconstruction rehabilitation program that was performed about 6 months (see table 1). Inclusion criteria of the study were: (1) isolated ACL injuries; (2) unilateral arthroscopic ACL reconstruction; (3) age between 21 and 31 years; (4); regular attendance, missing no more than three sessions of ACL surgery rehabilitation in the first three months after ACL reconstruction. According to the aim of research, 36 men who had experienced ACL reconstruction randomly were divided into three groups: taping $(\mathrm{N}=12)$, non- taping $(\mathrm{N}=12)$ and placebo $(\mathrm{N}=12)$ groups. The instruments used were Siemens Isokinetic dynamometer (Iso 2 model, made in Italy), 3NS TEX (made by Korea) Kinesio tape, IKDCSKE form and SECA Scale (weight and height, made in Germany).Research procedure was explained verbally to the subjects. After adjusting isokinetic dynamometer for each subject, they performed 8 repetitions with a speed of $360^{\circ}$ /s as a warm up set. The test protocols consisted of 2 repetitions in 3 sets with a speed of $300 \%$, 2 repetitions in 3 sets with a speed of $180 \%$ s and 2 repetitions in 3 sets with a speed of $60 \%$. They rested 10 seconds between each set and 120 seconds between stages 1 to 3 .

According to study of Kase et al (2003) Kinesio tape is applied for both "muscle facilitation" and "muscle inhibition" technique. KT applying from the muscle origin to insertion with stronger tension (50 to $75 \%$ ) of its original length may enhance muscle contraction. On the contrary, muscle contraction may be reduced by applying KT from the muscle insertion to origin with weaker, tension (15 to $25 \%$ ) of its original length. So, Three different quadriceps taping modes were applied (no taping, placebo taping and taping) for three groups. The Tex was used from origin to insertion of the quadriceps muscle ( $50 \%$ tension by length), around and below the patella bone as KT (experimental) group (Fig1). According to the study of Vithoulka et al (2010), for placebo group two levels Tex were applied transverse on quadriceps muscle. One of Tex $5 \mathrm{~cm}$ above the middle distance of the femur and the other one $5 \mathrm{~cm}$ below were applied (Fig 2).As mentioned three groups (no taping, placebo taping and taping) performed testing protocol before and 24 hours after taping in the same room and environmental circumstances such as light, noise, temperature and wet. By using SPSS 19 data was analyzed. Descriptive statistics was used for measurement of Average, Standard Deviation, variance and interpretive analysis was applied for frequency tables and ANOVA and post hoc test (LSD) within three groups.

\section{Results}

According to the table 3 in the hamstring muscles, significant effects were obtained at velocities of $60 \%$, $180^{\circ} / \mathrm{s} \& 300 \%$ s. Furthermore, there were significant effects in the quadriceps muscles at velocities of $180 \% \mathrm{~s}$ and $300 \%$ s 48 hours after taping $(\mathrm{P}<0.05)$.

Table 1. ACL reconstruction rehabilitation programs

\begin{tabular}{lll}
\hline Weeks & Rehabilitation program & Sessions \\
\hline 1 to 4 & $\begin{array}{l}\text { Electrotherapy on Reducing pain, Inflammation, edema, achieving ROM and } \\
\text { IKDCSKEF test }\end{array}$ & 5 per weeks \\
\hline 5 to 8 & $\begin{array}{l}\text { Limiting hemarthrosis, pain and edema, obtaining full ROM and full weight } \\
\text { bearing, gait training and IKDCSKEF test }\end{array}$ & 3 per weeks \\
\hline 9 to 12 & $\begin{array}{l}\text { Neuromuscular, Core, balance, PNF stretching, proprioceptive exercises and } \\
\text { IKDCSKEF test }\end{array}$ & 2 or 3 per weeks \\
13 to 16 & Running, agility and IKDCSKEF test & 2 or 3 per weeks \\
17 to 20 & Plyometrics, TRX exercises and IKDCSKEF test & 2 per weeks \\
21 to 24 & Access better, fair H/Q ratio and IKDCSKEF test & 2 per weeks \\
25 to 28 & Intermediate specific exercise in related sports functional and IKDCSKEF tests & 3 per weeks \\
29 to 32 & Advanced specific exercise in related sports functional and IKDCSKEF tests & 3 or 4 per weeks \\
\hline 33 to 36 & Return to sport by specific and skill tests & \\
\hline
\end{tabular}




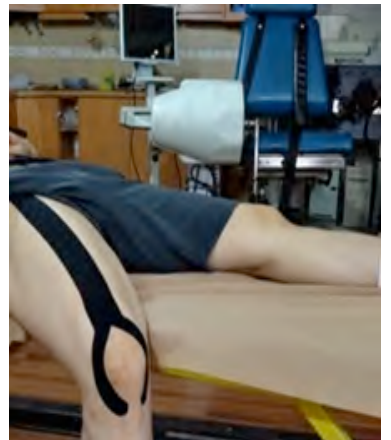

Fig 1. The model of taping in the taping group.

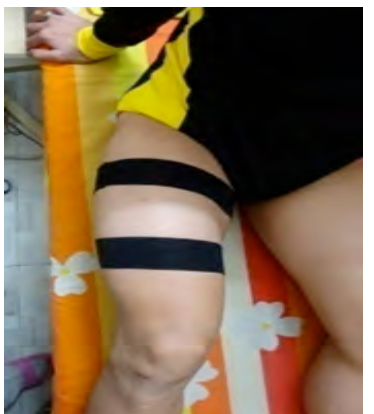

Fig 2. Model of taping in the placebo group

Table 3. The mid - term effects ( 24 hours) of Kinesio Tape on peak power among groups

\begin{tabular}{|c|c|c|c|c|c|c|}
\hline Muscles & $\begin{array}{l}\text { Angular } \\
\text { Velocities } \% \text { s }\end{array}$ & Group & $\begin{array}{l}\text { Peak power } \\
\text { Pre-test } \\
\text { Mean (SD) }\end{array}$ & $\begin{array}{l}\text { Post-test } \\
\text { Mean (SD) }\end{array}$ & $\mathbf{F}$ & P-Value \\
\hline \multirow{9}{*}{ Hamstring } & \multirow{4}{*}{60} & No taping & $151(38.63)$ & $153.77(41.12)$ & 0.631 & 0.546 \\
\hline & & Taping & $149.44(90.82)$ & $169.34(55.05)$ & 1.831 & $0.031 *$ \\
\hline & & Placebo & $150.31(48.36)$ & $152.01(45.74)$ & 1.276 & 0.243 \\
\hline & & No taping & $208.12(42.89)$ & $216.12(87.65)$ & 0.529 & 0.611 \\
\hline & \multirow{3}{*}{180} & Taping & 211.37 (79.84) & 241.51 (88.09) & 2.423 & $0.035^{*}$ \\
\hline & & Placebo & 210.65 (84.05) & 216.07 (67.17) & 0.059 & 0.955 \\
\hline & & No taping & $355.22(31.22)$ & 368.1 (83.98) & 0.483 & 0.642 \\
\hline & \multirow{3}{*}{300} & Taping & 357.12 (64.69) & 408.07 (78.01) & 2.384 & $0.041^{*}$ \\
\hline & & Placebo & $356.87(156.76)$ & 371.51 (91.04) & 0.158 & 0.879 \\
\hline \multirow{9}{*}{ Quadriceps } & & No taping & $149.11(31.89)$ & $149.98(39.04)$ & 0.281 & 0.542 \\
\hline & \multirow{2}{*}{60} & Taping & 150.66 (42.05) & 163.29 (41.01) & 1.981 & 0.098 \\
\hline & & Placebo & $152.77(12.44)$ & $157.4(45.7)$ & 1.100 & 0.088 \\
\hline & \multirow{5}{*}{180} & No taping & $219.12(52.01)$ & 221.37 (44.53) & 0.182 & 0.860 \\
\hline & & Taping & 226.62 (51.35) & 282.05 (47.32) & 4.037 & $0.005^{*}$ \\
\hline & & Placebo & $2187.5(33.7)$ & $228.87(41.86)$ & 0.366 & 0.059 \\
\hline & & No taping & $370(56.05)$ & 379.45 (77.05) & 0.208 & 0.262 \\
\hline & & Taping & $373.19(79.2)$ & 410.67 (87.87) & 2.640 & $0.033^{*}$ \\
\hline & 300 & Placebo & $372.29(55.02)$ & 390.75 (86.09) & 3.195 & 0.061 \\
\hline
\end{tabular}

\section{Discussion}

In quadriceps and hamstring muscles there were significant effects at velocities of $180 \%$ s and $300 \%$ s 24 hours after taping. Of course in quadriceps muscle, significant effects were obtained at velocity of $300 \%$ in the placebo group. Studies have used the output strength or peak torque but limited studies have directly evaluated the peak power of the femur's muscles among unhealthy athletes. However, peak power and torque in different angular velocities can be fair criteria for explosive movement of the femur's muscles. It has been reported that peak power is generated at velocities of $60 \%$ s \& $180^{\circ}$ s. It also has been found that measurements of power can be useful in describing the types of deficits seen in some patient types. Isoifidou et al (2000) found that increase in angular velocity lead to increase in peak power of the femur's muscles [20, 21]. Herington et al (2004) figured out that use of tape is ineffective [22]. It seems that difference in the mentioned results and present study may be due to tension, type or method of taping and samples (healthy ans injured). Takey et al (2007) obtained significant differences in peak power between left and right leg among elderly females and suggested that peak torque is representative of work and power and may be the only necessary parameter for isokinetic muscle performance testing of the extensor muscles of the knee in the elderly [23]. Fu et al (2008) found no significant difference in muscle power among the three conditions and believed that KT on the anterior thigh neither decreased nor increased muscle strength in healthy non-injured young athletes [24]. They examined the possible delayed (12 hours after taping) effects of $\mathrm{KT}$ on muscle strength in the quadriceps and hamstring when taping is applied to the anterior thigh of 14 healthy young athletes in taping and control groups while in this study muscular power was assessed in athletes (men) who had ACL reconstruction and significant effects of KT on peak power at velocities of $180 \%$ s and $300 \%$ s 24 hours after taping in the quadriceps and hamstring muscles was observed. The inconsistency in the above results and present study may be attributed to difference in tension (30\% vs 50\%), type, method and time of taping (12h vs $24 \mathrm{~h}$ ), samples (healthy and injured) and groups. Vithuolk et al (2010) taped their samples (nonathletic female) in different manner. Of course their taping had significant effect on peak torque. Nelson (2011) obtained significant decrease in maximum power post- intervention, and no significant differences in the average power, or average 
and maximum speed and cadence measurements [24]. Forty asymptomatic trained amateur cyclists performed two $1.5 \mathrm{~km}$ time trials pre- and post- KT application and Peak power of quadriceps muscles was studied by him while this study was performed on men who had ACL reconstruction and obtained significant effect (mid - time) of KT on power. Wong et al (2012) showed that despite of taping, work out of samples (14 healthy male and 16 healthy female) were decreased by using KT [26]. In fact, type and stretching of taping (tension) can cause decrease of work out and peak power among healthy people. They reported that decreasing of peak power in extension is visible and more than flexion while in this research the result indicated in quadriceps and hamstring muscles there were significant effects at velocities of $180^{\circ} / \mathrm{s}$ and $300 \%$ s at the 24 hours after taping. Subjects of Wong et al (2012) were healthy that had more decrease in extension than flexion whiles our subjects were men who had ACL reconstruction. Wong et al (2012) studied the effect of taping on output peak power at velocities of 60, 120 and $180 \%$ s while in the present study taping and its effect were studied at velocities of 60, 180 and $300 \%$ s. They evaluated peak power on quadriceps muscles and obtained decrease in power while the present study investigated the effect KT on peak power of hamstring and quadriceps muscles and obtained increase in peak power. With respect to these results it can be concluded that taping (our model and $50 \%$ tension) can improve peak power before plyometric exercise in rehabilitation protocols. So using tape in rehabilitation phase and starting of explosive exercises is suggested for improving of functional muscles, increasing in peak torque and strength and prevention of re-injury. Wong et al (2012) tested before and immediately after taping while this study tested before and 24 hours after taping. Lumbroso et al (2014) studied effect of KT (30\% tension) application over hamstring on peak force among 36 physical therapy students (27) while our subjects were men who had ACL reconstruction and taped 50\% tension. They found no immediate change of peak force in the hamstring group, however, two days later, peak force significantly increased that agrees with parts of the results of the present study. It has been figured out significant effects at 24 and 48 hours after taping compared with before taping in taping group [12]. They believed that using tape has a positive impact on explosive muscle performance and power in a vertical jump test that is compatible with the result of the present study. The isokinetic test (open chain exercise) involves one joint and segment, it limits the knee angular velocity and biarticular muscles (rectus femoris) are affected only by one joint (knee) since there is no simultaneous movement of adjacent joints. In contrast, the squat vertical jump test involves both legs, it is a closed chain exercise, the knee angular velocity is not limited and there is a transfer of energy from other joints so output power increases. However, according to reports of Nadali (2014), the positive effect of taping during the 24 and 48 hours after taping is effective on vertical jump or Sargent and results of the present study indicates increase of strength output of the femur's muscles among athletes who had ACL reconstruction. So, taping can cause psychological positive effects, knee stability and adaptability (proprioceptive receptors) of the knee joint. Sera et al (2015) has not found significant differences in the variables assessed between KT and Micropore conditions or among testing sessions (pre, post, and 24h after) and no statistical significance for interaction between tape conditions and testing session [28]. They evaluated the effects of KT on knee extension force in soccer players while the present study tested the peak power of the femur's muscles in athletes who had ACL reconstruction that agrees with the parts of the result of the present study. Guedes et al (2016) reported that there were no significant differences on time of taping at 24 and 48 hours and KT did not enhance knee extensor neuromuscular performance of healthy men at different muscle action velocities between 60 to $240 \%$ s [29] but this study obtained significant effects of KT on muscular power in the quadriceps and hamstring muscles at velocities of $180 \%$ s and $300 \%$ s 24 hours after taping. It can be stated the difference in their results and present study may be due to tension ( $0 \%$ and $40 \%$ vs $50 \%$ ), subjects (healthy vs Injured), type or method and time (duration) of taping. On the other hands, it has been verified that KT has positive effects in individual's postACL reconstruction during returning to pre-injury activity level and/or sport [30].

\section{Conclusion}

It seems that the use of KT has a positive impact on peak power of quadriceps and hamstring muscles at the start of the powers' program of the rehabilitation on unhealthy athletes who have ACL reconstruction. Apart from the psychological impact, taping by stabilizing the knee joint may result in significant impact. Use the proper tension of taping makes optimum traction to touch receptors, stimulating more skin deep motor neurons and thereby increase the torque and peak power of the femur's muscles. Increasing stability in the joint of athletes can cause more daring and courage among athletes who have injury and can reach them to higher muscular peak power during plyometric exercises or explosive activity. Therefore, using mid - term taping (24 hours later) with the proper tension (50\%) like model of the present study can be recommended (Mehregan model) in the start of the power's program of the rehabilitation athletes who have ACL reconstruction. Other influences of KT among other injured athletes need to be addressed in further research efforts.

\section{Acknowledgement}

The present research was done under finance supporting of Islamic Azad University, Torbat-e Heydarieh Branch, Iran. The researchers would like to thank the finance supporter, participants and physiotherapists of the Mehregan clinic in Mashhad.

\section{Conflict of interests}

The authors declare that there is no conflict of interests. 


\section{References:}

1. Khabaz MH, Khabazan AM, Ariamanesh ASH, Hoseleh A, Nadali S, Bakhshizade A, Atri AE. The effect of short time taping on concentric peak torque of knee muscles after ACL reconstruction. The Journal of Sports and Physical Education (PHOTHON). 2013;24(111): 175-80.

2. Garrick JG, Requa RK. Anterior cruciate ligament injuries in men and women: how common are they? Am Academy of Orthop Surg. 2001;1-10.

3. Dodwell ER, LaMont LE, Green DW, Pan TJ, Marx RG, Lyman S. 20 years of pediatric anterior cruciate ligament reconstruction in New York State. The American journal of sports medicine. 2014;29(3): 675-680.

4. Thomas AC, Wojtys EM, Brandon C, Palmieri-Smith RM. Muscle atrophy contributes to quadriceps weakness after anterior cruciate ligament reconstruction. Journal of Science and Medicine in Sport. 2016;19(1): 7-11.

5. Chmielewski TL, Wilk KE, Snyder-Mackler L. Changes in weight-bearing following injury or surgical reconstruction of the ACL: relationship to quadriceps strength and function. Gait \& posture. 2002;16(1): 87-95.

6. De Jong SN, van Caspel DR, van Haeff MJ, Saris DB. Functional assessment and muscle strength before and after reconstruction of chronic anterior cruciate ligament lesions. Arthroscopy: The Journal of Arthroscopic \& Related Surgery. 2007; 31(1):21-e1.

7. Konishi Y, Ikeda K, Nishino A, Sunaga M, Aihara Y, Fukubayashi T. Relationship between quadriceps femoris muscle volume and muscle torque after anterior cruciate ligament repair. Scandinavian journal of medicine \& science in sports. 2007;17(6):656-61.

8. Hall E, Bishop DC, Gee TI. Effect of plyometric training on handspring vault performance and functional power in youth female gymnasts. PloS one. 2016;11(2): e0148790.

9. Slupik A, Dwornik M, Bia1oszewski D, Zych E. Effect of Kinesio Taping on bioelectrical activity of vastus medialis muscle. Preliminary report. Ortopedia, Traumatologia, Rehabilitacja. 2007;9(6): 644-651.

10.Thelen M, Dauber JA, Stoneman PD. The clinical efficacy of Kinesio tape for shoulder pain: a randomized, doubleblinded, clinical trial. Journal of Orthopaedic \& Sports Physical Therapy. 2008;38(7): 389-395.

11. Yeung SS, Yeung EW. Acute Effects of Kinesio Taping on Knee Extensor Peak Torque and Stretch Reflex in Healthy Adults. Medicine. 2016;95(4): e2615.

12.Nadali S, Amel KM, Aryamanesh AS, Hoseleh A, Khabaz $\mathrm{MH}$, Bakhshizadeh A. The effect of Kinesio taping on Vertical Jump after ACL reconstruction. International Journal of Sport Studies. 2014; 4 (6): 653-658.

13.Vithoulka I, Beneka A, Malliou P, Aggelousis N, Karatsolis $\mathrm{K}$, Diamantopoulos K. The effects of Kinesio-Taping ${ }^{\circledR}$ on quadriceps strength during isokinetic exercise in healthy non athlete women. Isokinetics and Exercise Science. 2010;18(1): 1-6.

14.Kase K, Wallis J, Kase T. Clinical therapeutic applications of the Kinesio taping_method. 1st ed: Ken Ikai Co Ltd, Tokyo; 2003.

15.Huang CY, Hsieh TH, Lu SC, Su FC. Effect of the Kinesio tape to muscle activity and vertical jump performance in healthy inactive people. Biomedical engineering online. 2011;10(1): 1-10.

16.De Almeida Lins CA, Neto FL, de Amorim ABC, de Brito Macedo L, Brasileiro JS. Kinesio Taping ${ }^{\circledR}$ does not alter neuromuscular performance of femoral quadriceps or lower limb function in healthy subjects: Randomized, blind, controlled, clinical trial. Manual Therapy. 2013;18(1): 4145

17.Morris D, Jones D, Ryan H, Ryan CG. The clinical effects of Kinesio ${ }^{\circledR}$ Tex taping: A systematic review. Physiotherapy theory and practice. 2013;1;29(4):259-70.

18.Williams S, Whatman C, Hume PA, Sheerin K. Kinesio taping in treatment and prevention of sports injuries. Sports medicine. 2012;42(2):153-64.

19.Csapo R, Alegre LM. Effects of Kinesio ${ }^{\circledR}$ taping on skeletal muscle strength-A meta-analysis of current evidence. Journal of Science and Medicine in Sport. 2015;18(4):450-6.

20.Iosifidou A, Giakas G, Koutsouki D, Baltzopoulos V. Peak Power Assessment Using Isokinetic And Vertical Jump Tests. Athens Pre-olympic Congress. 2004. Jul. Sport Science Through the Ages: Challenges in the New Millennium.

21.Iossifidou A N, Baltzopoulos V. Peak power assessment in isokinetic dynamometry. European journal of applied physiology. 2000;82(1-2), 158-160.

22.Herrington L. The effect of patella taping on quadriceps strength and functional performance in normal subjects. Physical Therapy in Sport. 2004;5(1), 33-36.

23.Takey K, Kandil OA, Abo Elazm SN. Isokinetic quadriceps peak torque, average power and total work at different angular knee velocities. 2007.

24.Fu TC, Wong AM, Pei YC, Wu KP, Chou SW, Lin YC. Effect of Kinesio taping on muscle strength in athletes-a pilot study. Journal of Science and Medicine in Sport. 2008;11(2):198-201.

25.Nelson DK. The effect of Kinesio ${ }^{a}$ tape on quadriceps muscle power output, length/tension, and hip and knee range of motion in asymptomatic cyclists. Doctoral dissertation. 2011.

26.Wong OM, Cheung RT, Li RC. Isokinetic knee function in healthy subjects with and without Kinesio taping. Physical Therapy in Sport. 2012;13(4):255-8.

27.Lumbroso D, Ziv E, Vered E, Kalichman L. The effect of kinesio tape application on hamstring and gastrocnemius muscles in healthy young adults. Journal of bodywork and movement therapies. 2014;18(1):130-8.

28.Serra MV, Vieira ER, Brunt D, Goethel MF, Gonçalves M, Quemelo PR. Kinesio Taping effects on knee extension force among soccer players. Brazilian journal of physical therapy. 2015;19(2):152-8.

29.Guedes R, Bottaro M, Magalhães I, Trindade M, Brown LE, Carmo JD, Carregaro RL. The effects of Kinesiotaping on quadriceps muscle performance at different velocities: A randomized controlled trial. Isokinetics and Exercise Science. 2016;24(2):149-156.

30.Harput G, Ulusoy B, Ozer H, Baltaci G, Richards J. External supports improve knee performance in anterior cruciate ligament reconstructed individuals with higher kinesiophobia levels. The Knee. 2016;25:11-16. 
Information about the authors:

Mahdi Amel Khabazan; http://orcid.org/0000-0002-2531-6824; Dr_khabazan@yahoo.com; Department of Physical Education and Sport Sciences, Torbat - e Heydarieh Branch, Islamic Azad University; Torbat -e Heidariyeh, Iran.

Hossein Soltani; http://orcid.org/0000-0003-3985-2385; soltani_hn@yahoo.com; Department of Physical Education and Sport Sciences, Torbat - e Heydarieh Branch, Islamic Azad University; Torbat -e Heidariyeh, Iran.

Cite this article as: Mahdi Amel Khabazan, Hossein Soltani. The mid - term effect of kinesio taping on peak power of quadriceps and hamstring muscles after anterior cruciate ligament reconstruction. Physical education of students, 2017;1:27-32. doi:10.15561/20755279.2017.0105

The electronic version of this article is the complete one and can be found online at: http://www.sportedu.org.ua/index.php/PES/issue/archive

This is an Open Access article distributed under the terms of the Creative Commons Attribution License, which permits unrestricted use, distribution, and reproduction in any medium, provided the original work is properly cited (http://creativecommons.org/licenses/by/4.0/deed.en)

Received: 9.01.2016

Accepted: 25.01.2017; Published: 10.02.2017 